\title{
Correction to: A case series of lateral opening wedge high tibial osteotomy for valgus malalignment
}

\author{
Brett Collins $^{1} \cdot$ Alan Getgood $^{2} \cdot$ Abdulaziz Z. Alomar $^{3} \cdot$ J. Robert Giffin ${ }^{2}$. \\ Kevin Willits $^{2}$ - Peter J. Fowler ${ }^{2} \cdot$ Trevor B. Birmingham $^{2} \cdot$ Robert B. Litchfield $^{2}$
}

Published online: 23 October 2017

(C) European Society of Sports Traumatology, Knee Surgery, Arthroscopy (ESSKA) 2017

\section{Correction to: Knee Surg Sports Traumatol \\ Arthrosc (2013) 21:152-160 \\ DOI 10.1007/s00167-012-2070-y}

Unfortunately, one of the co-author affiliation was incorrect in the original publication of this article. The correct affiliation is given below:

Abdulaziz Z. Alomar

King Khalid University Hospital, College of Medicine, King

Saud University, Riyadh, Saudi Arabia.

The online version of the original article can be found under doi:10.1007/s00167-012-2070-y.

Robert B. Litchfield

rlitchf@uwo.ca

1 Brisbane Orthopaedic and Sports Medicine Centre, 259

Wickham Tce, Brisbane, QLD 4000, Australia

2 Fowler Kennedy Sport Medicine Clinic, University of Western Ontario, 3M Centre, London, ON N6A 3K7, Canada

3 King Khalid University Hospital, College of Medicine, King Saud University, Riyadh, Saudi Arabia 